\title{
Converter Configuration Suitable For Electronic Distribution Transformer
}

\author{
Ashok Kumar \\ M.Tech(Power Electronics) \\ E. E. E Dept.IVNRVJIET \\ Hyderabad, India
}

\author{
N.Krishna Kumari \\ Assoc Professor \\ E. E. E Dept.IVNRVJIET \\ Hvderabad. India \\ M.P.Soni \\ Professor \\ E. E. E Dept.IVNRVJIET \\ Hyderabad, India
}

\author{
Dr.G.S.Raju \\ Professor \\ E. E. E Dept.IVNRVJIET \\ Hyderabad, India
}

\begin{abstract}
A proposed AC to AC matrix converter which is suitable for electronic transformer is without energy storage elements will be analyzed as part of this paper. A Matrix Converter with 18 IGBTs and 22 diodes achieves the desired variable voltage, variable frequency performance using a three stage circuit. In the first stage three phase normal frequency voltage is converted to single phase high frequency voltage which in turn is converted to a pulsating DC voltage in the second stage. In the final stage three phase variable amplitude variable frequency voltage is generated from this pulsating DC voltage.
\end{abstract}

The full text of the article is not available in the cache. Kindly refer the IJCA digital library at www.ijcaonline.org for the complete article. In case, you face problems while downloading the full-text, please send a mail to editor at editor@ijcaonline.org 